$48-15$ ys(d)

PREPARED FOR THE U.S. DEPARTMENT OF ENERGY, UNDER CONTRACT DE-AC02-76-CHO-3073

PPPL-3118

PPPL-3118

MEASUREMENTS OF DT ALPHA PARTICLE LOSS NEAR THE OUTER MIDPLANE OF TFTR

BY

S.J. ZWEBEN, D.S. DARROW, H.W. HERRMANN, ET AL.

JULY 1995
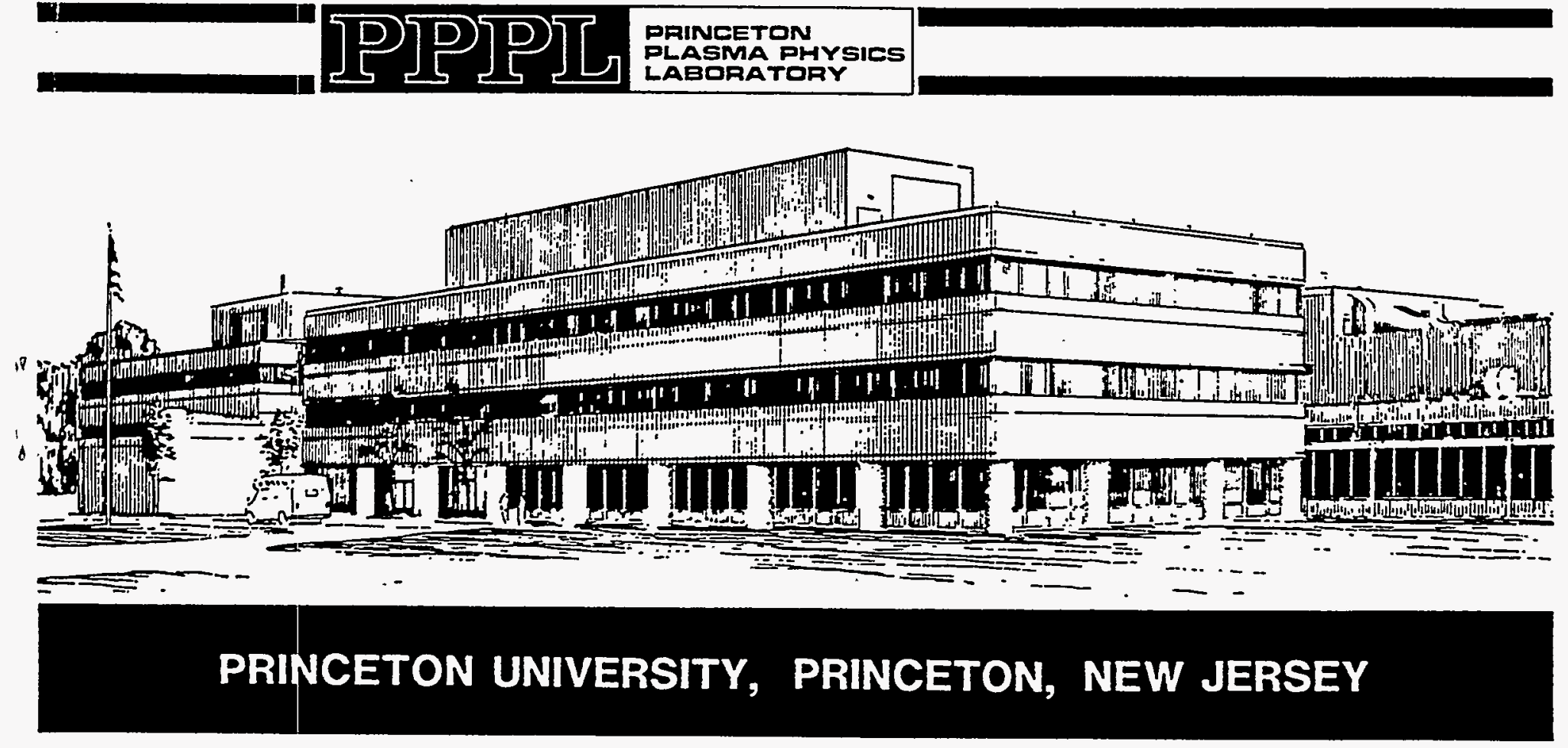


\section{NOTICE}

This report was prepared as an account of work sponsored by an agency of the United States Government. Neither the United States Government nor any agency thereof, nor any of their employees, makes any warranty, express or implied, or assumes any legal liability or responsibility for the accuracy, completeness, or usefulness of any information, apparatus, product, or process disclosed, or represents that its use would not infringe privately owned rights. Reference herein to any specific commercial produce, process, or service by trade name, trademark, manufacturer, or otherwise, does not necessarily constitute or imply its endorsement, recommendation, or favoring by the United States Government or any agency thereof. The views and opinions of authors expressed herein do not necessarily state or reflect those of the United States Government or any agency thereof.

\section{NOTICE}

This report has been reproduced from the best available copy. Available in paper copy and microfiche.

Number of pages in this report: 26

DOE and DOE contractors can obtain copies of this report from:

Office of Scientific and Technical Information

P.O. Box 62

Oak Ridge, TN 37831 ;

(615) 576-8401.

This report is publicly available from the:

National Technical Information Service

Department of Commerce

5285 Port Royal Road

Springfield, Virginia 22161

(703) $487-4650$ 


\section{DISCLAIMER}

Portions of this document may be illegible in electronic image products. Images are produced from the best available original document. 


\title{
Measurements of DT Alpha Particle Loss Near the Outer Midplane of TFTR
}

\author{
S. J. Zweben, D. S. Darrow, H. W. Herrmann, \\ M. H. Redi, J. Schivell, R. B. White
}

Princeton Plasma Physics Laboratory, P.O. Box 451, Princeton, N.J. 08543

\begin{abstract}
Measurements of DT alpha particle loss to the outer midplane region of TFTR have been made using a radially movable scintillator detector. The conclusion from this data is that mechanisms determining the DT alpha loss to the outer midplane are not substantially different from those for DD fusion products. Some of these results are compared with a simplified theoretical model for TF ripple-induced alpha loss, which is expected to be the dominant classical alpha loss mechanism near the outer midplane. An example of plasma-driven MHD-induced alpha particle loss is shown, but no signs of any "collective" alpha instability-induced alpha loss have yet been observed.
\end{abstract}




\section{Introduction}

This paper describes the initial measurements of DT alpha particle loss near the outer midplane region of TFTR. These results are of interest for clarifying the process of toroidal field (TF) ripple-induced loss of alpha particles, which is expected to be the dominant classical loss mechanism for alpha particles at high current in TFTR (I $\geq 1.5 \mathrm{MA}$ ), and in ITER[1]. These results complement the excellent studies of $\mathrm{TF}$ ripple diffusion reported at this conference from JT-60U[2], JET[3], and Tore Supra[4].

To a large extent, the results of these new measurements of DT alpha loss near the midplane are very similar to those obtained previously for $\mathrm{DD}$. fusion products[5,6]. This is to be expected if both the DT and DD fusion product losses are due to classical TF ripple loss, since the gyroradius and collisionality of these fusion products are similar. On the other hand, these midplane measurements differ significantly from the previous DT alpha loss measurements made at the vessel bottom, which were found to be consistent with classical first-orbit loss[7]. Again, this is to be expected, since the TF ripple loss is expected to occur only at poloidal angles $\leq 30^{\circ}$ below the outer midplane, whereas the first-orbit loss is expected to be peaked $\approx 60-90^{\circ}$ below the outer midplane.

The basic experimental results are presented in Sec. 2, including comparisons between DT and DD measurements. Sec. 3 contains a comparisons of the DT results with a simplified model of classical TF ripple loss based on the collisionless MAPLOS code[6], and a Summary.

\section{Experimental Results}

Measurements of the DT alpha loss were made using a scintillator detector located $20^{\circ}$ below the outer midplane of the TFTR vessel, i.e. $36 \mathrm{~cm}$ below the midplane in the ion grad-B drift direction. A photograph of the detector head inside the TFTR vacuum vessel is shown in Fig. 1. This "midplane" detector is essentially the same used previously for DD fusion product measurements[5,6], the main difference being that the $3 \mu \mathrm{m}$ aluminum foil filter which was used previously has been removed (to allow measurements of low energy neutral beam ions)[8].

This detector is similar to the other detectors in the lost alpha poloidal array[9], in which a pinhole/slit aperture pair disperses the fast ions in pitch angle and gyroradius before they hit a scintillator screen. The visible light image produced by the alphas is transferred to both a camera and to a set of photomultiplier tubes. The acceptance range of the midplane detector includes particles, with pitch angles (with respect to the local toroidal field) of $\approx 45-85^{\circ}$, and gyroradii in the range of $\approx 2-10 \mathrm{~cm}$ (perpendicular to the toroidal field B), which includes alpha particles down to an energy of $\approx 0.5 \mathrm{MeV}$, but excludes alphas which may be trapped inside 
the TF ripple wells at pitch angles $\geq 85^{\circ}$. The midplane probe is radially movable, whereas the other probes are fixed.

An important consideration in these midplane probe measurements is the relative location of the probe's aperture with respect to the limiters inside the vessel. The probe's radial position will be defined here with respect to the geometrical shadow of the "RF" limiters, which are at a radius of $99 \mathrm{~cm}$ with respect to the vessel center. Alpha particle loss can be detected behind this outer limiter shadow since the nearest such limiter is displaced $\geq 2 \mathrm{~m}$ toroidally from the midplane probe in the direction from which the alphas are incident onto it (i.e. from the co-I direction). A detailed interpretation of the shadowing effect of these limiters has been considered previously for DD fusion products[5], but is beyond the scope of the present paper.

\subsection{Plasma Current and Fusion Power Dependence}

The first midplane DT alpha loss measurements were made during the plasma current scan over $\mathrm{I}=0.6-2.0 \mathrm{MA}$ described in Ref. 7. These plasmas had a major radius of $R=2.52 \mathrm{~m}$, a toroidal field of $\mathrm{B}=4.7-5.1 \mathrm{~T}$, and a neutral beam injection power (NBI) power of $P=5-13 \mathrm{MW}$. The midplane probe aperture for all these discharges was at $1.7 \mathrm{~cm}$, i.e. $1.7 \mathrm{~cm}$ radially outward from the geometrical shadow of the (toroidally displaced) limiter. Note that the midplane probe was not inserted into the highest-powered, highest current discharges of Ref. 7 due to the possibility of probe damage during major disruptions.

The DT alpha particle signals were integrated over the midplane probe acceptance ranges in pitch angle and gyroradius, and then normalized to the global DT neutron rate during the time of interest, which was typically the quasi-steady-state period $0.4-0.7 \mathrm{sec}$ after the start of NBI. The resulting relative alpha particle loss per DT neutron vs. plasma current is shown at the top of Fig. 2.

The current dependence of the normalized DT alpha loss shown in Fig. 2 is at least qualitatively similar to the results obtained previously for DD fusion products[6]. The most striking feature in this DT data is a sharp decrease in normalized alpha loss below $I=1.0 \mathrm{MA}$, in contrast to the monotonically increasing loss toward lower currents observed in the $90^{\circ}$ detector DT data for the same discharges[7]. This difference is not too surprising, since in the limit of zero current the alphas will drift vertically downward into the $90^{\circ}$ detector, and not into the $20^{\circ}$ detector.

For a closer comparison of DT with DD data, the top part of Fig. 2 also shows $D D$ fusion product loss data taken for $R=2.52 \mathrm{~m}$ plasmas made just before the DT run. The DD data is normalized to the DT data at $\mathrm{I}=1.0 \mathrm{MA}$. The variation of normalized alpha loss vs. plasma current is very similar for DT and DD fusion products. The alpha signal levels per DT neutron are 
$\approx 1.5$ times those for DD fusion products per DD neutron. This is similar to the ratio seen in the $90^{\circ}$ detectors, and is expected from the relative scintillation efficiency for the respective fusion products[7].

The fusion power dependence of the midplane alpha loss at a constant current of $I=1.8 \mathrm{MA}$ is shown at the bottom of Fig. 2, again for $\mathrm{R}=2.52 \mathrm{~m}$ plasmas with the probe aperture at $1.7 \mathrm{~cm}$. The relative alpha loss per DT neutron does not increase with fusion power, indicating the absence of any new "collective" alpha loss process up to fusion power levels of $\approx 4 \mathrm{MW}$. In fact, the normalized alpha loss actually decreases slightly with increasing fusion power over this range, despite the increase in Shafranov shift with increasing fusion power, also shown in Fig. 2. This is somewhat surprising, since an increased Shafranov shift should qualitatively tend to move the alpha source region to a higher TF ripple region, thus increasing the relative TF ripple loss.

\subsection{Time Dependence}

The time dependence of the midplane alpha loss signals normalized by the global DT neutron rate is shown in Fig. 3. At the top of Fig. 3 are results taken from the camera images for typical I=1.0 MA and I=1.8 MA discharges during the current scan of Fig. 2, in which the probe aperture located $1.7 \mathrm{~cm}$ behind the limiter shadow. The alpha loss rate vs. time does not vary by more than about $\pm 20 \%$ between 0.1 sec after the start of NBI to $0.1 \mathrm{sec}$ after the end of NBI (which is comparable to the uncertainty in these measurements). Similar behavior was seen in the other DT and DD discharges in the current scan of Fig. 2 (although in some other cases an increase in loss v.s. time at this aperture position has been seen).

A more accurate measurement of the time dependence of the midplane alpha loss is shown in the bottom part of Fig. 3, where in this case the data was taken from a photomultiplier tube integrating over the whole scintillator plane. In this I=2.0 MA discharge the probe aperture was located $1.0 \mathrm{~cm}$ inside the limiter shadow, which resulted in a very large signal level (see Sec. 2.3). The normalized alpha loss rate vs. time did not vary by more than about $\pm 20 \%$ between $\approx 0.05 \mathrm{sec}$ after the start of NBI to $\approx 0.6$ sec after the end of NBI, over which time the DT source rate varied by more than an order of magnitude.

The conclusion from this data is that there is generally no sign of an increase in the neutron-normalized alpha loss following the end of NBI, as might be expected from a slow diffusive loss process. In fact, the measured time dependence of the alpha loss to the outer midplane was similar to that seen in the $90^{\circ}$ detector, which was consistent with a prompt loss process such as first-orbit loss[7]. Further analysis is underway to reconcile this experimental result with recent modeling of collisional TF ripple loss in TFTR, which suggested that following the rapid first-orbit and collisionless stochastic ripple loss processes, an equally large loss fraction of alphas due 
to collisional processes is expected, delayed over the alpha slowing down time $[10,11]$.

\subsection{Radial Midplane Probe Scan}

The midplane probe was scanned radially during a long series of DT and $D D$ discharges with constant $R=2.52 \mathrm{~m}, I=2.0 \mathrm{MA}$ and $\mathrm{P} \approx 20-25 \mathrm{MW}$, with results shown in Fig. 4. In this figure, both the total alpha loss signal levels per DT neutron and also the total DD fusion product signal per DD neutron are shown, both averaged over an interval of $0.5 \mathrm{sec}$ during quasisteady-state phase of NBI as measured by the camera. The probe aperture was scanned within about $\pm 1.5 \mathrm{~cm}$ of the of the outer limiter radius. Note that at its innermost position the midplane probe tip was still $16 \mathrm{~cm}$ away from the plasma edge, so it did not heat up significantly.

The resulting profiles of the neutron-normalized alpha signal vs. radial probe position show qualitatively similar behavior for DT and DD fusion products. The shape of the DD curve is also similar to that measured previously in $R=2.45 \mathrm{~m}$ plasmas (note that the tip can not be scanned past the limiter radius in $R=2.6 \mathrm{~m}$ plasmas). The ratio of signal per neutron for $\mathrm{DT}$ is $\approx 1.5$ times that of $\mathrm{DD}$ for most of the radial range, which is similar to the ratio seen for the $90^{\circ}$ signals at this current. There does, however, seem to be a systematic increase in the ratio of DT/DD signal levels at the outermost probe position, which is similar to the relatively high DT/DD ratio at $I=1.8 \mathrm{MA}$ shown at the top of Fig. 2. Note that in these DD discharges the residual DT reaction rate due to recycling of tritium from the vessel walls was about $1 / 2$ the $\mathrm{DD}$ reaction rate.

The conclusion from this data is that mechanisms determining the radial profile of the measured DT alpha loss to the midplane probe are not substantially different from those for DD fusion products. This suggests the absence of any new mechanism of alpha loss at the location, e.g. collective alpha-instability induced alpha loss. However, a quantitative interpretation of the large increase in these signals as the probe moves inward has not yet been made; presumably, this is due to the increasingly localized collection of ions which would otherwise have been distributed over a larger wall area. Also, a quantitative decomposition of this signal in terms of the relative contributions from $\mathrm{TF}$ ripple loss and first-orbit loss has not yet been made (see Sec. 3.2).

\subsection{Pitch Angle and Gyroradius Distributions}

The scintillator images can be transformed into maps of the detected alpha particle pitch angle " $\chi$ " (where $\cos \chi=v_{\text {tor }} / v$ ) and gyroradius " $p$ " (defined for $X=90^{\circ}$ ) distributions, as described previously[7]. These maps are displayed in terms of the expected locations of the centroids of the impact positions for alphas of a given $X$ and $\rho$. The finite aperture 
dimensions and optical resolution cause the alpha distributions to be spread over the scintillator even for a single $(X, \rho)$, particularly in the $\rho$ direction.

Figure 5 shows some examples of $(X, \rho)$ maps for the midplane probe signals for four such similar $I=2.0 \mathrm{MA}$ discharges at $\mathrm{R}=2.52 \mathrm{~m}$ with $\approx 23$ MW of fusion power, as used for Fig. 4. Intensity contour maps are shown for probe positions of $\pm 1.5 \mathrm{~cm}$ for DT and very similar DD discharges, each of which is averaged over the 3.5-4.0 sec in discharges like that shown at the bottom of Fig. 3. Note that the signal levels for the $-1.5 \mathrm{~cm}$ position were $\approx 20$ times those for the $+1.5 \mathrm{~cm}$ position.

The first thing to notice from Fig. 5 is that there are only slight differences between the DT and DD data at a given probe position. This implies that the fusion product loss processes are substantially the same for the DT and DD plasmas, in agreement with the conclusion reached from the radial scans of Fig. 4 . Note that there was again a residual DT reaction rate of about $1 / 2$ the $\mathrm{DD}$ reaction rate in these $\mathrm{DD}$ discharges due to recycling of tritium from the vessel walls.

The second thing to notice from Fig. 5 is that the pitch distributions shift to a lower pitch angle as the probe is moved inward from the $+1.5 \mathrm{~cm}$ to the $-1.5 \mathrm{~cm}$ positions, both for the DT and DD cases. The peak pitch angle of $\approx 52^{\circ}$ for the signals at $-1.5 \mathrm{~cm}$ corresponds to orbits which are near to the "fattest bananas" of birth-energy alphas, while the peak pitch angle of $\approx 62^{\circ}$ for the signals at $+1.5 \mathrm{~cm}$ corresponds to more deeply trapped orbits with their banana tips in the stochastic TF ripple loss region (see Sec. 3.2). This result seems different from that reported in Ref. 6 , in which the peak near $62^{\circ}$ increased with respect to the first-orbit loss peak at $53^{\circ}$ as the probe was moved radially inward. However, the scan of Ref. 6 was made only between 3.7 and $6.2 \mathrm{~cm}$ behind the outer limiter shadow for $\mathrm{R}=2.6 \mathrm{~m}$ plasmas, and so can not be directly compared with the results of Fig. 5 .

The third thing to notice from the maps of Fig. 5 is that there are only small differences between the gyroradius distributions of DT and DD fusion product losses at either probe position. The $\approx 5 \%$ larger gyroradius peak location for the DT cases compared to the DD cases may simply be due to the $\approx 10 \%$ larger gyroradius for expected for $3.5 \mathrm{MeV}$ alphas compared with 3 $\mathrm{MeV}$ protons or $1 \mathrm{MeV}$ tritons from $\mathrm{DD}$ (after taking into account the component of DT alphas). There is also little or no change in the gyroradius (i.e. energy) distribution of alpha loss vs. time, suggesting that these midplane probe signals are primarily due to a relatively "prompt" alpha loss mechanism, as also inferred from the time dependences in Sec. 2.2 .

Figure 6 shows the time dependence of the $(\chi, \rho)$ maps for $I=2.0 \mathrm{MA}$ discharges similar to that shown at the bottom of Fig. 3 , in which the probe aperture position was at $-1.5 \mathrm{~cm}$ for all cases. The upper-left map was taken $\leq 0.04$ sec after the start of NBI, i.e. well before any collisional effects 
could influence the TF ripple diffusion, while the lower maps were taken at 0.25 and $0.65 \mathrm{sec}$ after the end of NBI, by which time any slow diffusive effects should be dominant, if present. To a first approximation, all the maps are all essentially the same, implying a relatively low level of slow diffusive alpha loss.

There is one anomaly in the interpretation of the gyroradius distributions which is not yet understood. The peak of these signals occurs at an inferred gyroradius centroid location of $\approx 5 \mathrm{~cm}$, whereas the expected peak location for prompt loss of alphas at $\approx 3.5 \mathrm{MeV}$ is $\approx 7 \mathrm{~cm}$. This difference is most likely due to a systematic error in the modeling of the impact position of the alphas onto the scintillator, since the difference between these two centroid locations is only $\approx 0.2 \mathrm{~cm}$ at the scintillator plane, or to an incomplete correction for the optical vignetting of these images, which is much larger than for the other detectors.

\subsection{Effects of MHD Activity}

The alpha loss to the outer midplane probe was sometimes affected by plasma-induced MHD activity, but in a way which was not qualitatively different from that previously seen for DD fusion products[12]. These MHDinduced changes in the alpha loss occurred during coherent modes, sawtooth crashes, ELMs during limiter H-modes[13], and major and minor disruptions.

One example of this behavior is shown in Fig. 7, in which the midplane alpha loss signal was monitored by a photomultiplier tube which integrated over the whole scintillator plane, as for the bottom of Fig. 3. During the strong coherent MHD activity between $\approx 3.6-4.1 \mathrm{sec}$ in this discharge, the alpha loss per DT neutron increased by up to $\approx 50 \%$ above that for similar discharges without MHD activity. This additional alpha loss fluctuates along with the normal internal low-n MHD activity, which eventually decreases in frequency and "locks" between 4.0-4.1 sec. Further analysis of this complicated behavior is beyond the scope of the present paper, although a model for such MHD effects has been developed previously[12].

No signs of any collective alpha-instability induced alpha loss to the midplane region has yet been seen in these DT experiments. This is consistent with the observation that no new fluctuations have been observed in DT plasmas which were not also observed in DD plasmas[14,15]. However, it should be noted that the midplane probe was not inserted for most of highest-powered, highest current plasmas, due to the possibility of disruption-induced damage to the probe: 


\section{Discussion}

This paper presented the first measurements of DT alpha particle loss to the outer midplane region of TFTR. These measurements were made using a movable scintillator detector located $20^{\circ}$ below the outer midplane, which was scanned $\pm 1.5 \mathrm{~cm}$ radially around the shadow of the outer poloidal limiter in plasmas with $\mathrm{R}=2.52 \mathrm{~m}$. The experimental results were quite clear and reproducible, but the theoretical analysis and interpretation of these results in terms of the expected TF ripple diffusion is still in a preliminary stage.

\subsection{Summary of Experimental Results}

a) The plasma current dependence of the neutron-normalized DT alpha loss had a peak at I $\approx 1.0 \mathrm{MA}$, similar to the current dependence of the DD fusion product loss, implying a similar loss process for DT and DD fusion products,

b) There was no systematic increase in the normalized DT alpha loss per neutron with increasing DT fusion power, implying that there was no "collective" alpha-instability induced alpha loss up to $\approx 4 \mathrm{MW}$ of fusion power,

c) The normalized alpha particle loss per neutron was usually constant as a function of time between $\approx 0.05 \mathrm{sec}$ after the start of NBI and $\approx 0.5 \mathrm{sec}$ after the end of NBI, suggesting that the alpha loss process was fairly "prompt",

d) The radial profiles of the detected DT alpha loss were similar to those for DD fusion product loss over the range $\pm 1.5 \mathrm{~cm}$ around the outer limiter shadow, over which the alpha collection rate varied by about a factor of 30 ,

e) The pitch angle and gyroradius distributions were similar between DT and $\mathrm{DD}$ discharges of the same type, with a systematic decrease in the pitch angle distribution as the probe was moved radially inward, again implying a similar loss process for DT and DD fusion products,

f) The gyroradius distributions did not vary significantly between $\approx 0.04 \mathrm{sec}$ after the start of NBI and $\approx 0.65 \mathrm{sec}$ after the end of NBI, suggesting the absence of a significant delayed loss component,

g) The midplane alpha loss could increase by up to $\approx 50 \%$ during large coherent plasma-induced MHD activity, but the behavior was qualitatively similar to that seen previously for DD fusion products. 


\subsection{Comparison with MAPLOS Modeling of TF Ripple Loss in TFTR}

The first detailed modeling of the TF ripple loss of fusion .products in TFTR was done using the MAPLOS code written by Boivin in connection with his midplane probe experiments on DD fusion products[5,6]. This code used a collisionless mapping model of trapped particle orbits, the bounce points of which were stepped vertically according the model of Goldston, White, and Boozer[16]. The magnetic geometry was simplified by assuming zero Shafranov shift, but the vacuum region between the plasma edge and the wall was properly taken into account in order to find the poloidal impact location of the escaping orbits at the wall. For these calculations, the wall was assumed to be a smooth toroidal surface, without any limiters.

Figure 8 shows the MAPLOS-calculated poloidal distribution of DT alphas for the $R=2.52 \mathrm{~m}$ plasmas in the current scan of Fig. 2. Each of the four cases represents a Monte Carlo run of $\approx 125,000$ alphas, which is enough to allow good statistics for the lost alpha distribution. For these runs the wall location was specified as the limiter radius of $99 \mathrm{~cm}$, i.e. corresponding to the aperture position of zero in Fig. 4. The results are generally similar to those obtained previously for $\mathrm{DD}$ fusion products[6], in which the TF ripple loss increases with plasma current and is localized $\leq 30^{\circ}$ below the outer midplane (the variation of the global and poloidal TF ripple loss and first-orbit loss vs. current was discussed in Ref. 4).

Taken literally, the model of Fig. 8 can not explain the peak in the midplane loss signal at I=1.0 MA seen in Fig. 2, since the calculated total alpha loss vs. plasma current at a poloidal angle of $20^{\circ}$ below the outer midplane monotonically decreases with increasing plasma current, as shown in Fig. 9. However, the alpha loss distributions at I $\geq 1.0 \mathrm{MA}$ (Fig. 8) are quite sensitive to the assumed poloidal angle, such that the calculated total loss at a poloidal angle of $\approx 10^{\circ}$ can explain (at least qualitatively) the peak in the data at I=1.0 MA, as also illustrated in Fig. 9. A quantitative interpretation of this current scan data will require a careful modeling of the finite alpha gyroradius and the shadowing by the limiter and the probe itself[5].

A different type of prediction from the MAPLOS code concerns the pitch angle distribution measured at the detector position. The measured peak pitch angle for the current scan data (Fig. 2) is shown in Fig. 10, along with MAPLOS calculations for the expected peak pitch angles for first-orbit and TF ripple loss. The measured peak pitch angle location does seem to agree with the model for TF ripple loss at high currents, as noted previously for DD fusion products[6], but the data does not seem to agree with the first-orbit model at the low current (where the TF ripple loss should be negligible). However, at I=0.6 MA the first-orbit loss consists of "pinch"-type orbits, which may be particularly sensitive to the assumed current distribution. 
The corresponding $3.5 \mathrm{MeV}$ alpha orbits at the peak pitch angles for the expected first-orbit and TF ripple loss for an I=2.0 MA plasma are shown in Fig. 10, along with an evaluation of the location of the stochastic TF ripple diffusion (SRD) region based on the GWB model. The measured pitch angle peak of $\approx 64^{\circ}$ corresponds to an orbit with its banana tip in the SRD domain, as expected for a TF ripple loss orbit. However, the orbit at $\approx 52^{\circ}$, which corresponds to the peak of the measured distribution when the probe is located $-1.5 \mathrm{~cm}$ with respect to the limiter, corresponds to a "fattest banana" orbit with its banana tip inside the SRD-free region. Evidently MAPLOS.can not explain the measured variation of the pitch angle peak vs. probe position shown in Fig. 5, since these calculated orbits do not change significantly over this range of aperture positions.

A final prediction of MAPLOS concerns the timescale for collisionless TF ripple diffusion of alphas in these discharges. The median loss time for TF ripple of alphas in this model was $\approx 10 \mathrm{msec}$, which is not inconsistent with the promptness of the alpha loss with respect to the neutron source discussed in Sec. 2.2, or with the constancy of the gyroradius distribution vs. time discussed in Sec. 2.4.

\subsection{Conclusions}

The measured behavior of DT alpha particles lost near the outer midplane of TFTR was found to be similar to the behavior measured for DD fusion products, as would be expected for any single-particle loss process such as TF ripple loss or first-orbit loss. No indication of any "collective" alpha-instability induced alpha particle loss process has been observed, although plasma-induced MHD activity could increase the alpha loss to the midplane by up to $\approx 50 \%$.

Many open questions remain to be resolved before these midplane probe measurements can be interpreted by a quantitative model for the TF ripple loss of alpha particles. Foremost among these is the need for better modeling of the actual detector geometry, including the finite alpha gyroradius and the geometrical shadowing effects of the midplane probe by the downstream poloidal limiter and by itself[5]. Such modeling seems to be necessary to explain the variation of measured alpha loss levels and pitch angle distributions with the radial probe position.

Another need is for more realistic modeling of the TF ripple loss itself, including the actual magnetic geometry and the collisional effects. Substantial progress has been made in this area using guiding center codes[10,11], although the statistics of these codes are necessarily limited when called upon to interpret the local loss to the midplane detector. Improvements can be made by first locating the ripple loss boundaries and then selectively following the orbits of only those alphas born near these boundaries[17]. 
Finally, it should be emphasized that these initial measurements of the DT alpha loss to the outer midplane were restricted to TFTR plasmas of a single size, and were limited to a range of pitch angles which did not include ripple-trapped alphas. Further experimental work is needed to examine the effects of the plasma major radius, the plasma current distribution, and various types of MHD activity on the alpha losses near the outer midplane region. Also, comparisons should be made between these alpha loss measurements and the measurements and modeling of the simultaneous effects of TF ripple loss and sawteeth on confined alphas in TFTR[18,19,20].

Acknowledgments: We thank R. L. Boivin, R.V. Budny, C.E. Bush, C.S. Chang, M. Diesso, H. Duong, J. Felt, E.D. Fredrickson, R.J. Hawryluk, D. Johnson, L. Johnson, G. Lemunyan, K. McGuire, H. E. Mynick, D. K. Owens, M. Petrov, B. Stratton, S.S. Medley, and V. Yavorski for various contributions to this work, which was supported by the US DOE Contract \#DE-AC02-76-CHO-3073.

\section{References}

1) S. Putvinski, et al, this conference

2) K. Tobita, et al, this conference

3) G. Sadler, et al, this conference

4) V. Basiuk, et al , this conference

5) R. Boivin and S.J. Zweben, Phys. Fluids B 5, 1559 (1993)

6) R. Boivin and S.J. Zweben, and R. B. White, Nucl. Fus. 33, 449 (1993)

7) S. J. Zweben, et al, to be published in Nucl Fus. (1995)

8) D.S. Darrow, et al, Rev. Sci. Inst. 63, 4562 (1992)

9) D. S. Darrow, et al, Rev. Sci. Inst. 66, 476 (1995)

10) M. H. Redi, et al, to be published in NF

11) M. H. Redi, et al, this conference

12) S.J. Zweben, et al, Phys. Plasmas 1 (5), 1469 (1994)

13) C.E. Bush, et al, Physics of Plasmas, to be published 1995

14) Z. Chang, et al, this conference

15) E.D. Fredrickson, et al, this conference

16) R. J. Goldston, R. B. White, and A. Boozer, Phys. Rev. Lett.

17) V. Yavorski, et al, this conference

18) M. Petrov, et al, this conference

19) R.V. Budny, et al, this conference

20) G. McKee, et al, this conference 


\section{Figure Captions}

1) Photograph of the midplane scintillator probe inserted into the TFTR vacuum vessel through the porthole on the upper right. The aperture into which the alpha particles enter is located $3 \mathrm{~cm}$ outward from the tip of the probe, inside of which is the scintillator screen. The nearly outer wall is $\approx 10 \mathrm{~cm}$ radially outward from the edge of the poloidal limiters, such as the one shown behind the probe. A similar poloidal limiter is $\approx 2 \mathrm{~m}$. toroidally in the incoming alpha direction. The midplane probe is radially movable between discharges.

2) The plasma current dependence of the neutron-normalized alpha loss to the midplane probe is shown at the top. The alpha loss per DT neutron peaks at $I \approx 1.0 \mathrm{MA}$, as does the $\mathrm{DD}$ fusion product loss per $\mathrm{DD}$ neutron in a similar current scan. The bottom part shows the neutron-normalized alpha loss.vs. fusion power for the $I=1.8 \mathrm{MA}$ DT discharges in the top part. For all cases the data was averaged over 0.4-0.7 sec after the start of NBI, and the probe aperture was $1.7 \mathrm{~cm}$ behind the limiter shadow (the Shafranov shifts are taken at $0.6 \mathrm{sec}$ after the start of NBI).

3) Time dependences of the neutron-normalized alpha loss to the midplane probe. The top part shows data from two of the discharges in the current scan of Fig. 2, in which the probe aperture was at $1.7 \mathrm{~cm}$ behind the limiter shadow, while the bottom part shows an I=2.0 MA discharge for which the probe was $-1.0 \mathrm{~cm}$ in front of the limiter shadow. In all cases the midplane alpha loss follows the DT neutron rate to within about $\pm 20 \%$.

4) Radial profiles of the DT and DD fusion product loss to the midplane probe as the aperture is scanned $\pm 1.5 \mathrm{~cm}$ around the shadow of the outer limiter. These discharges were all at $\mathrm{I}=2.0 \mathrm{MA}$ and $\mathrm{R}=2.52 \mathrm{~m}$, and the data was integrated over 0.7-1.2 sec after the start of NBI for discharges like that at the bottom of Fig. 3. The DT signal levels per neutron are about 1.5 times higher than those in $\mathrm{DD}$, as expected for the different scintillator efficiencies for different types of fusion products.

5) Intensity contour maps of the gyroradius centroid vs. pitch angle distributions for fusion product loss in DT and DD plasmas for discharges like those in Fig. 4. The contours represent a linear scale in the relative signal level for that scintillator image, after background subtraction. There is no substantial difference between the DT and DD patterns at a given probe position, such as would be expected for either TF ripple or first-orbit loss processes. However, the pitch angle distribution shifts toward lower pitch angle as the probe in moved farther inward, which is not understood.

6) Intensity contour maps of the gyroradius centroid vs. pitch angle distributions for DT alpha particle loss for various times during an I=2.0 MA discharge like that shown at the bottom of Fig. 3. There are only slight differences in these patterns between $0.04 \mathrm{sec}$ after the start of NBI and 0.65 
sec after the end of NBI. This suggests the absence of a significant delayed loss component, which would appear as a low-gyroradius feature at late times.

7) The effect of plasma-driven MHD activity on the midplane alpha loss can be seen as $a \approx 50 \%$ increase in the alpha loss per DT neutron over 3.6-4.1 sec in this discharge. The oscillations in the alpha loss are in phase with the dominant low-n MHD frequencies. Similar behavior has been seen for DD fusion product loss.

8) MAPLOS calculations of the poloidal distribution of TF ripple and firstorbit alpha loss in TFTR discharges, which models the current-scan data of. Fig. 2. The TF. ripple loss is localized $\leq 30^{\circ}$ below the outer midplane, similar to the DD fusion product loss calculated previously[6]. The vertical scales are all in the same units. In these calculations the wall is simplified to be a flat surface at the limiter radius.

9) The relative alpha loss vs. plasma current for the MAPLOS calculations of Fig. 8, plotted for poloidal angles of $20^{\circ}$ (the actual probe angle) and also $10^{\circ}$ : below the outer midplane. The current dependence is a sensitive function of the assumed poloidal angle. The data of Fig. 2 fits the $10^{\circ}$ curve better than the $20^{\circ}$ curve. This discrepancy may be due to an incomplete modeling of the finite alpha gyroradius and shadowing effects.

10) Variation of the pitch angle peak of the measured alpha loss vs. plasma current for the data of Fig. 2, compared with MAPLOS calculations of the expected peaks of the first-orbit and TF ripple loss distributions. At high currents I $\geq 1.8 \mathrm{MA}$ the data fit the model for TF ripple loss, as expected. At I=0.6 MA the first-orbit losses are of the "pinch" type, which do not fit the measured peak location, and there are negligible TF ripple losses. The orbits for $3.5 \mathrm{MeV}$ alphas entering the midplane probe at pitch angles of $52^{\circ}$ and $64^{\circ}$ are shown in the bottom for an $\mathrm{I}=2.0 \mathrm{MA}$ plasma. These orbits are calculated backward from an aperture position of $1.5 \mathrm{~cm}$ behind the outer limiter, but the orbits are basically unchanged over the range into +2 to- 2 $\mathrm{cm}$ with respect to the outer limiter. 


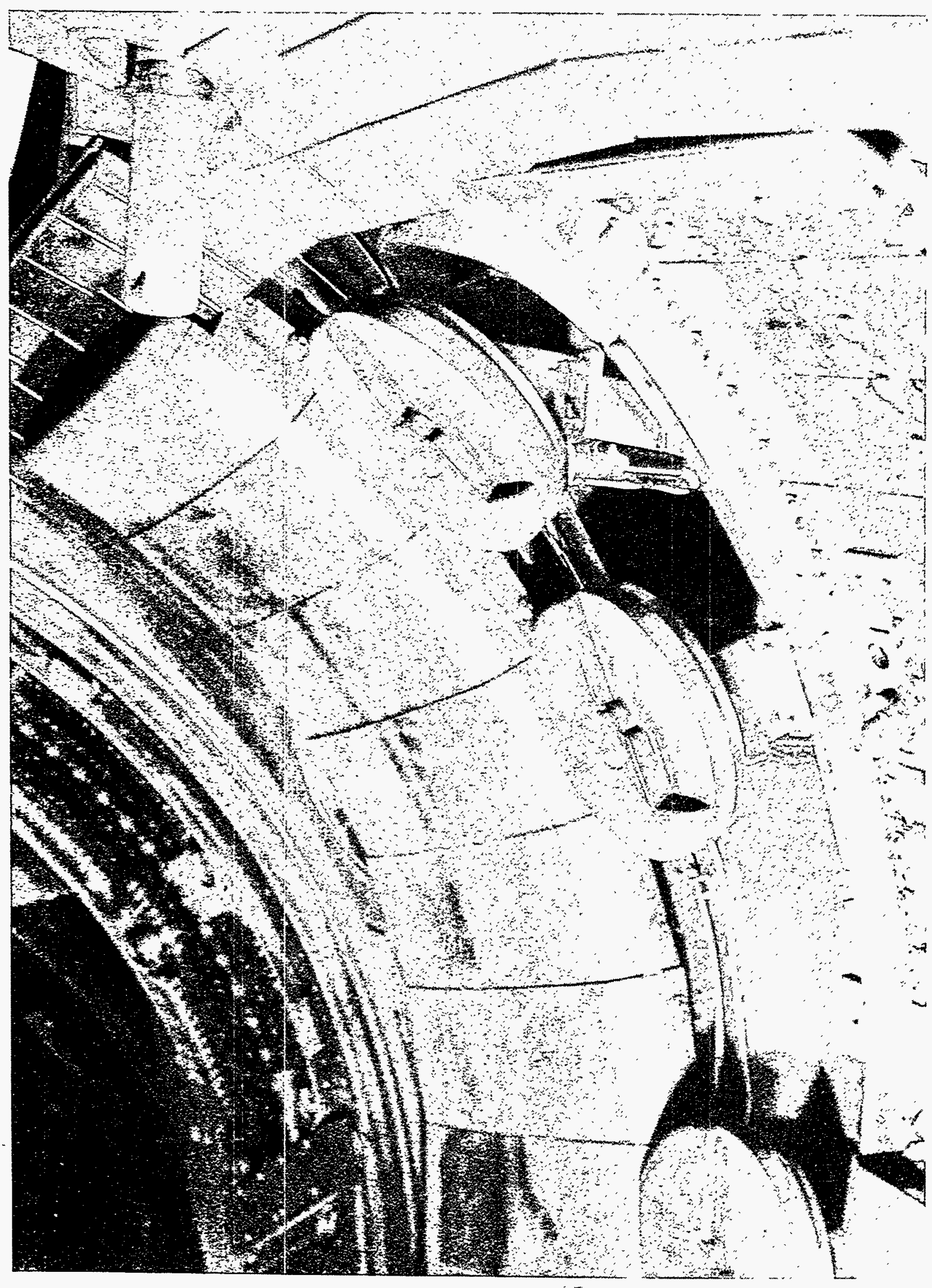

Fig. 1 

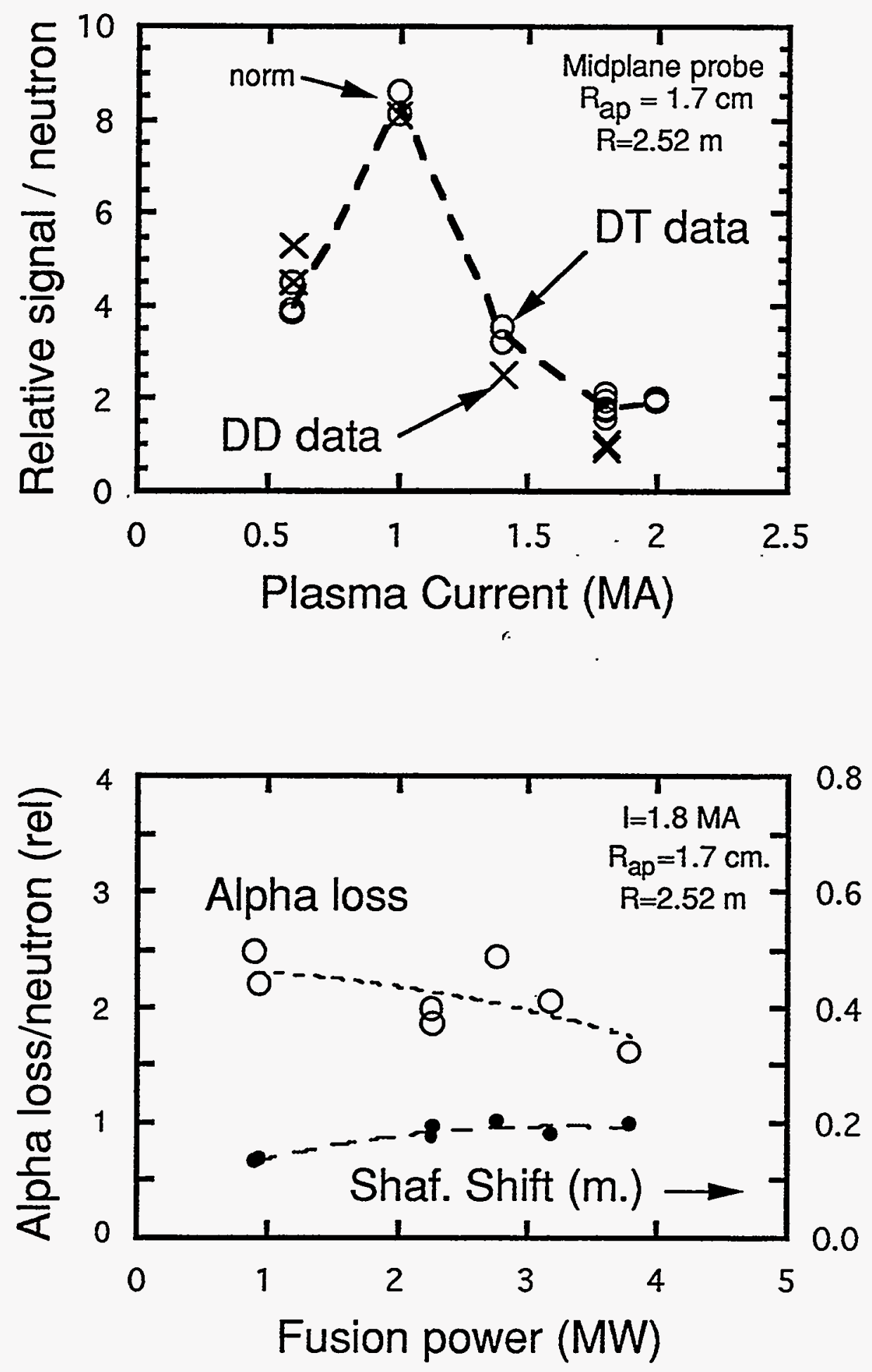

Fig. 2 

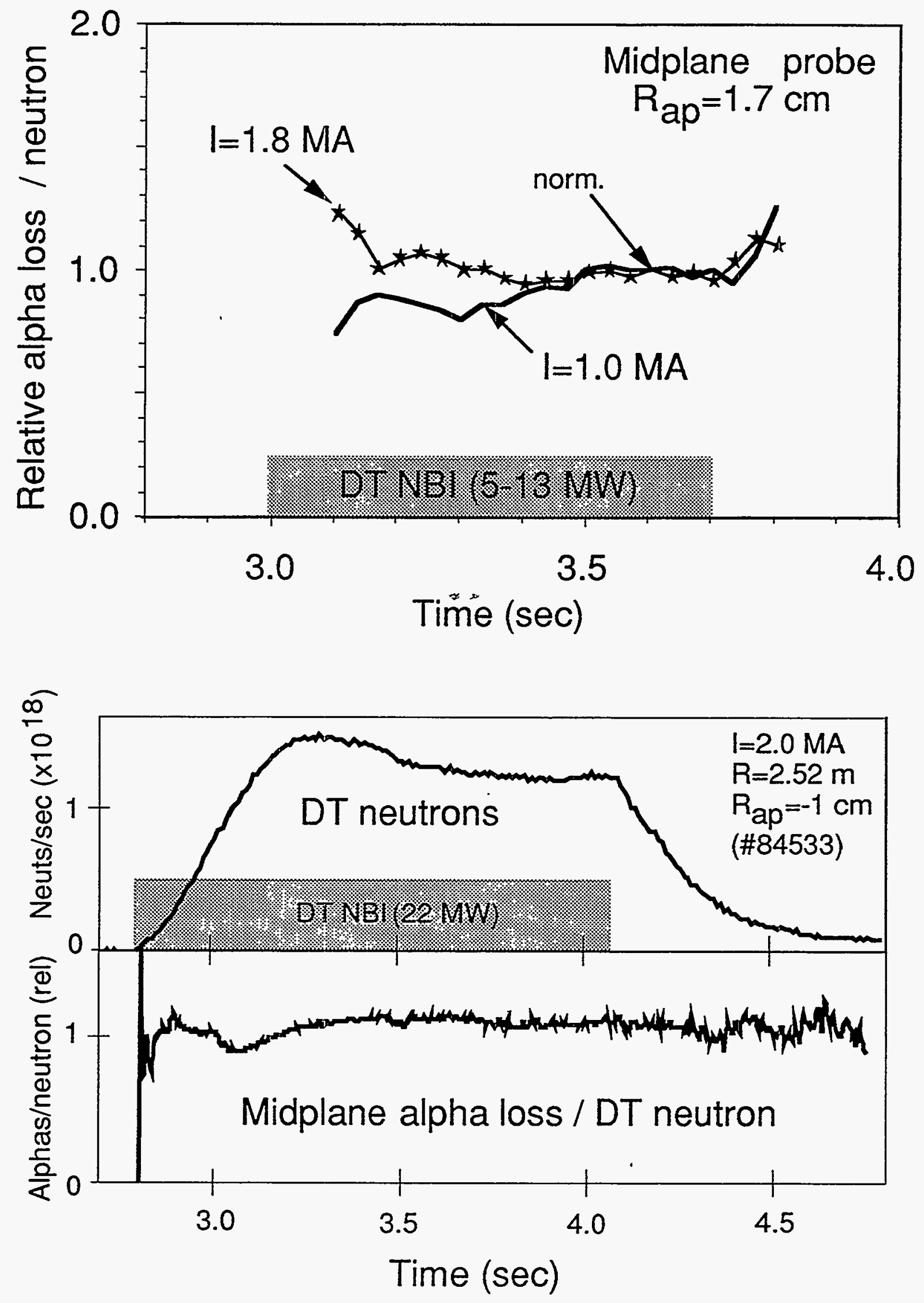

Fig. 3 


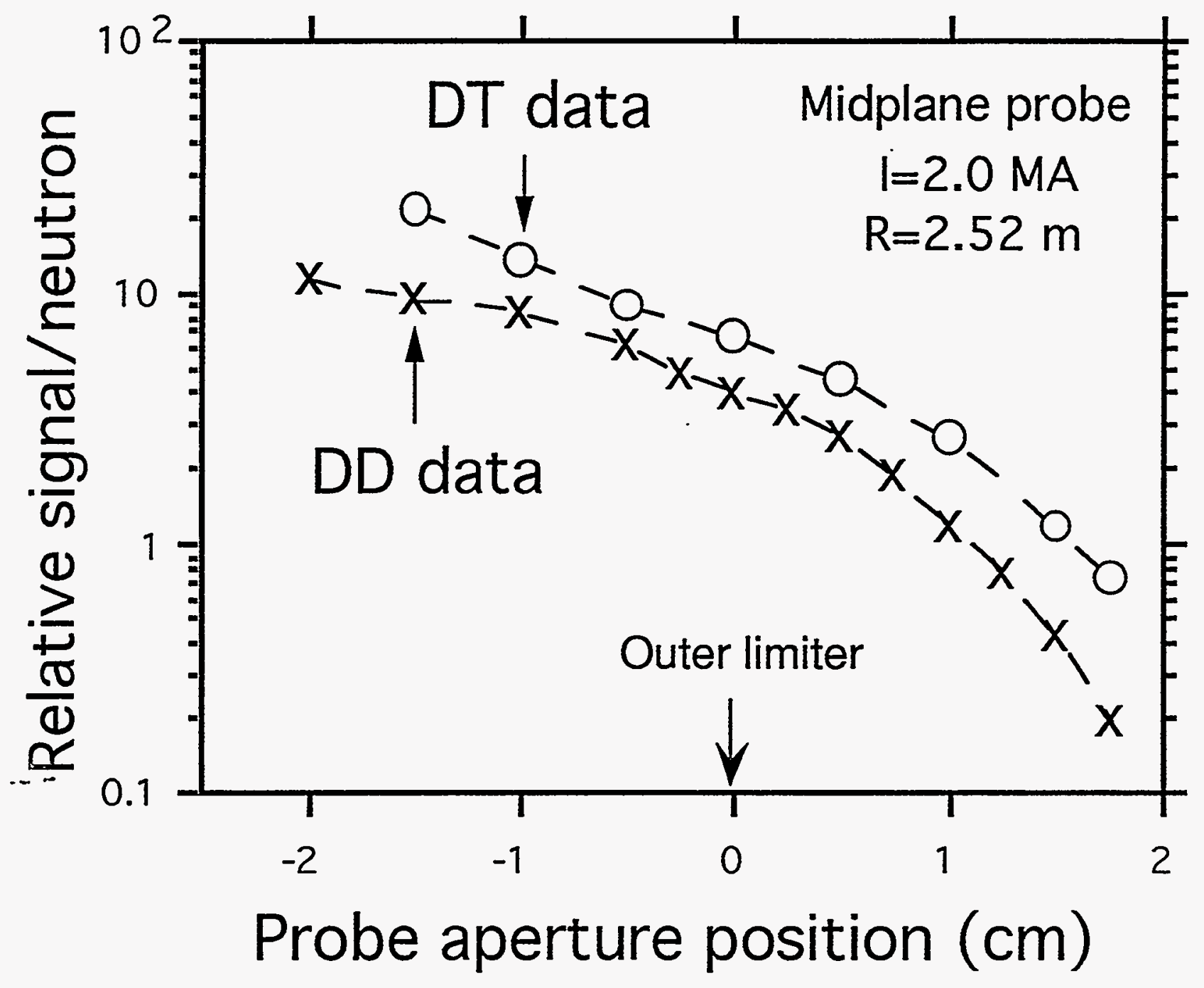

Fig. 4 

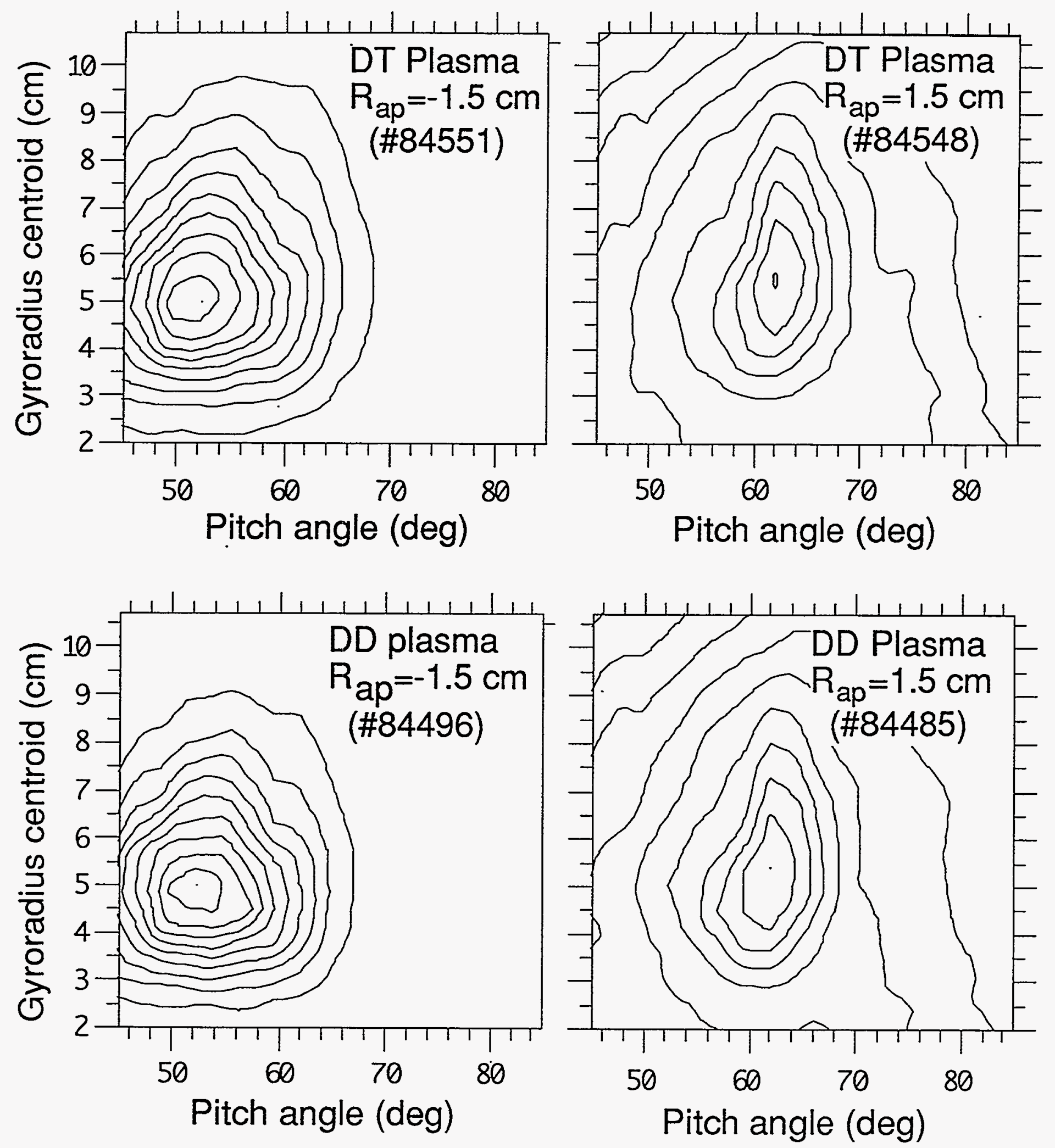

Fig. 5 

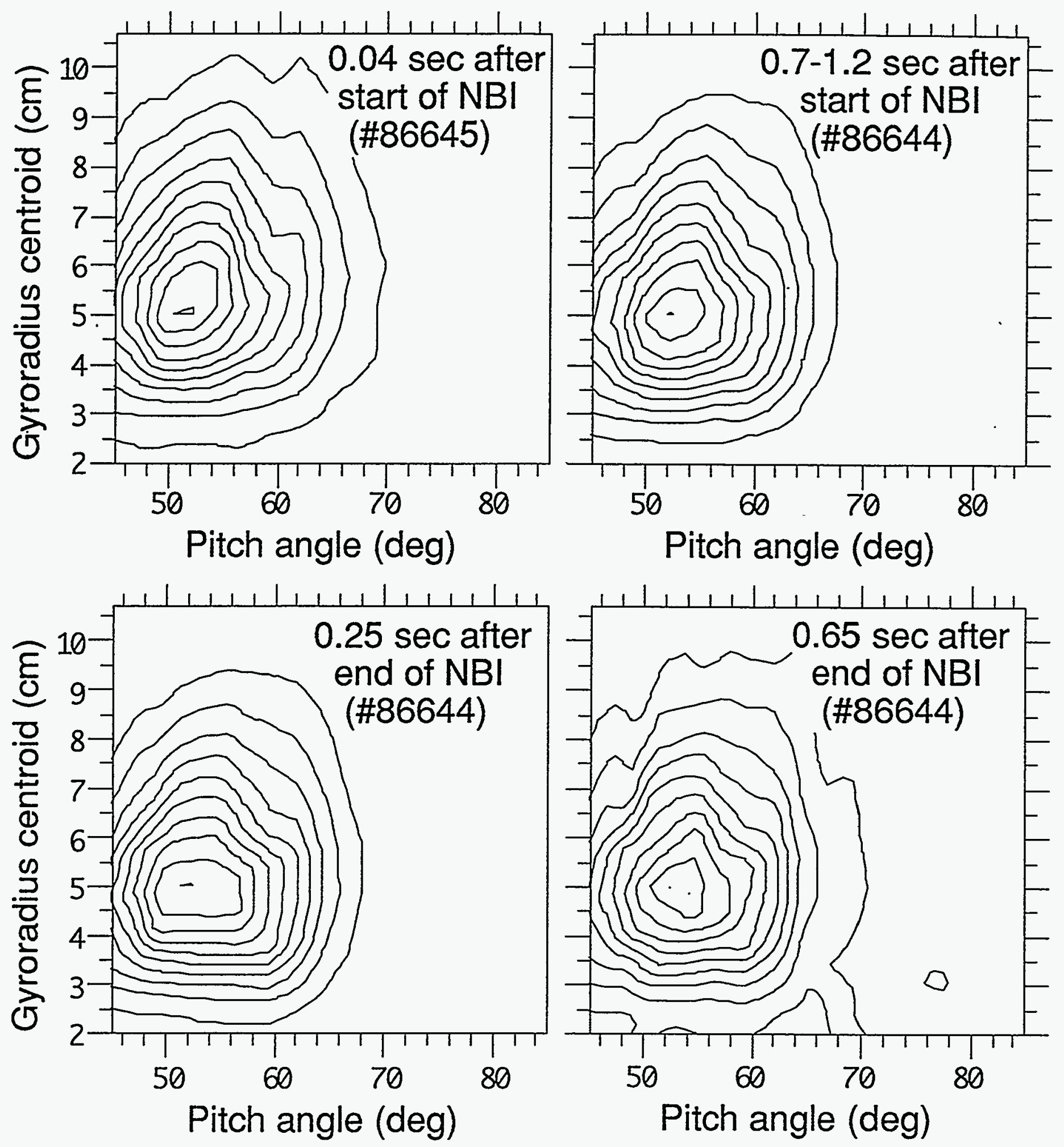

Fig. 6 


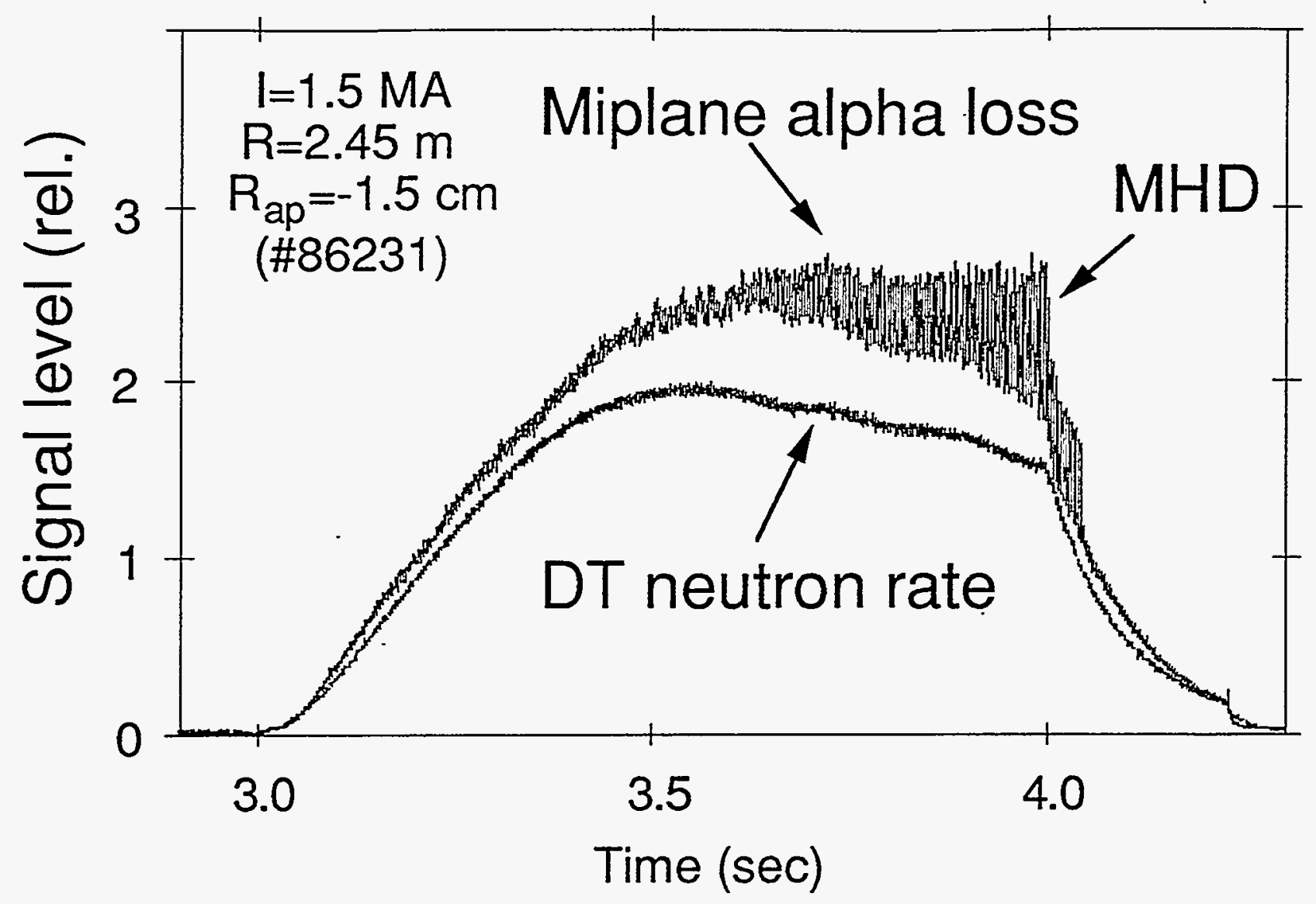

Fig. 7 

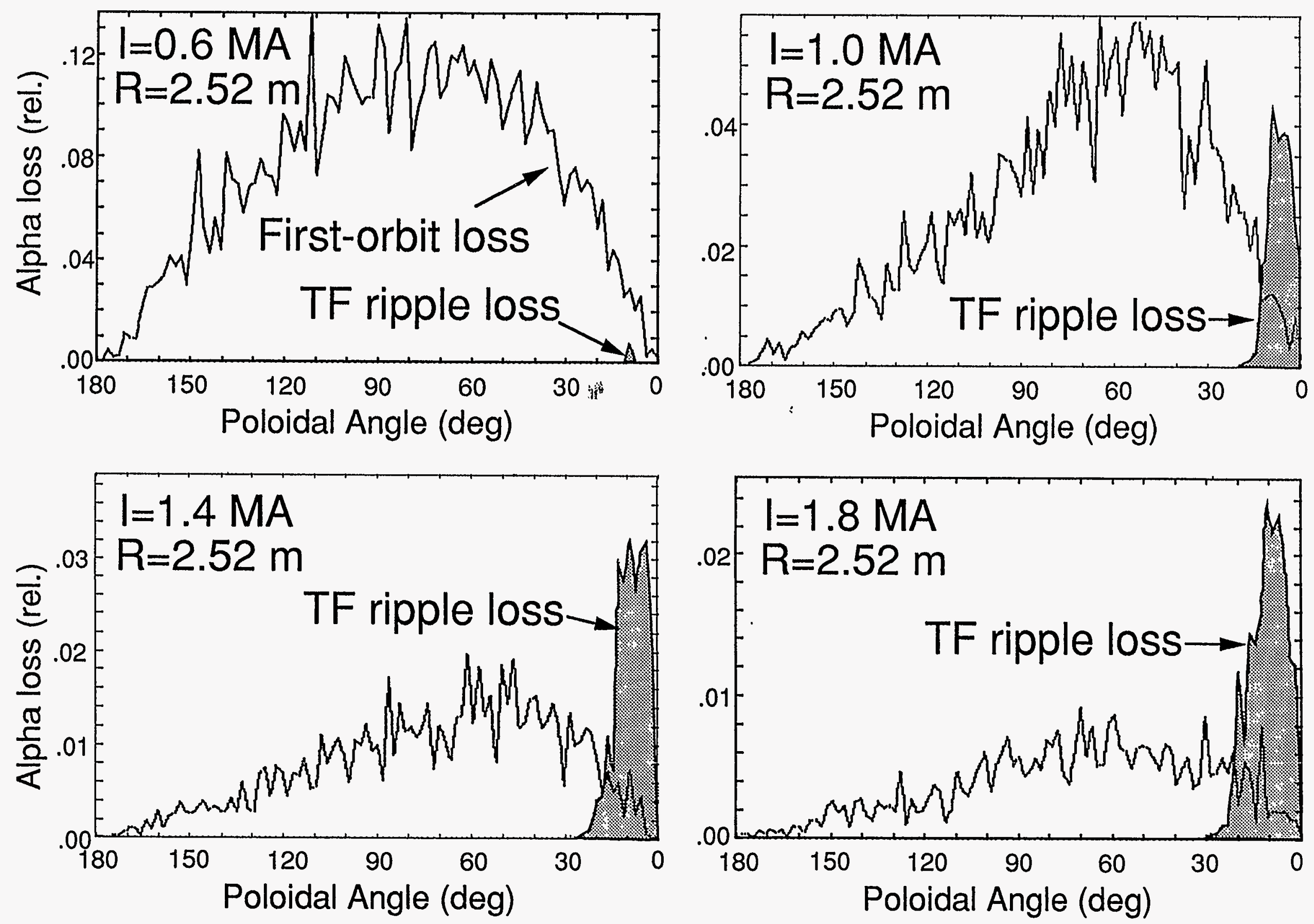


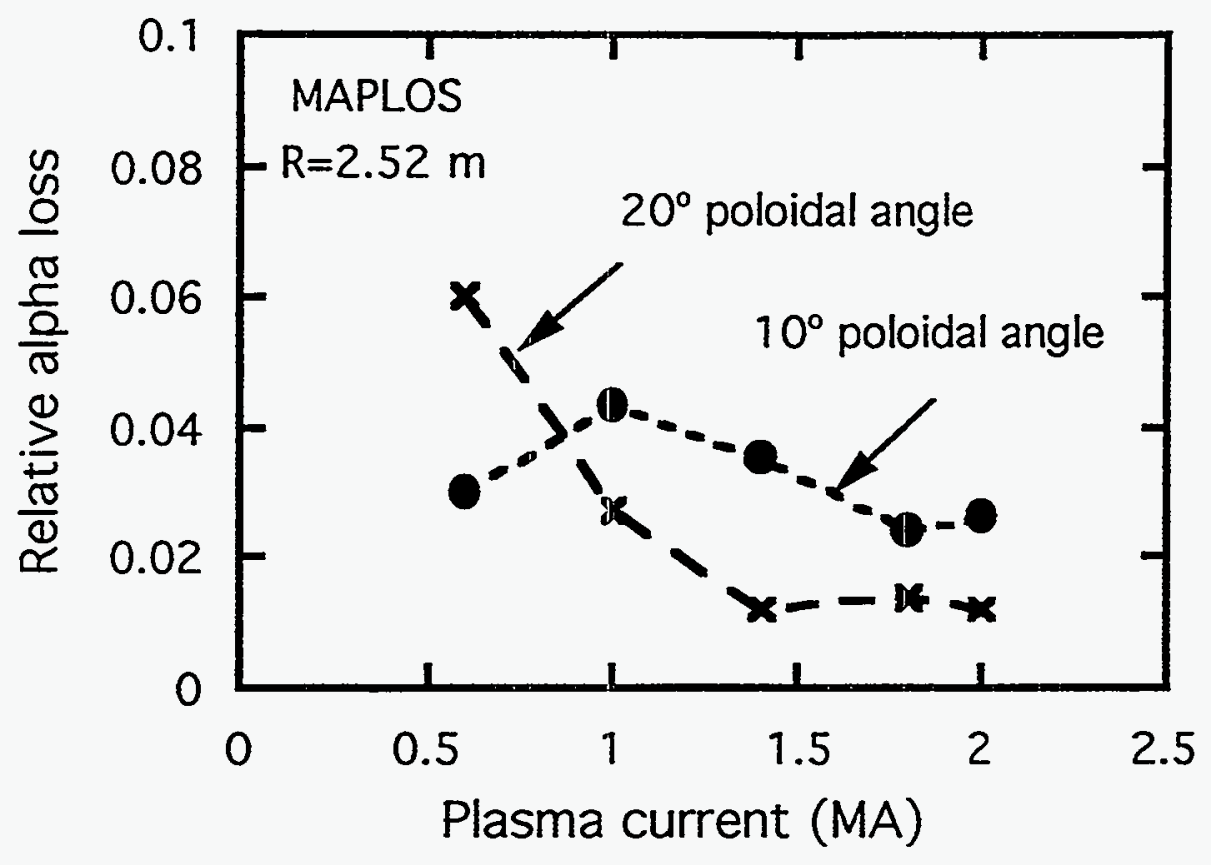

Fig. 9 

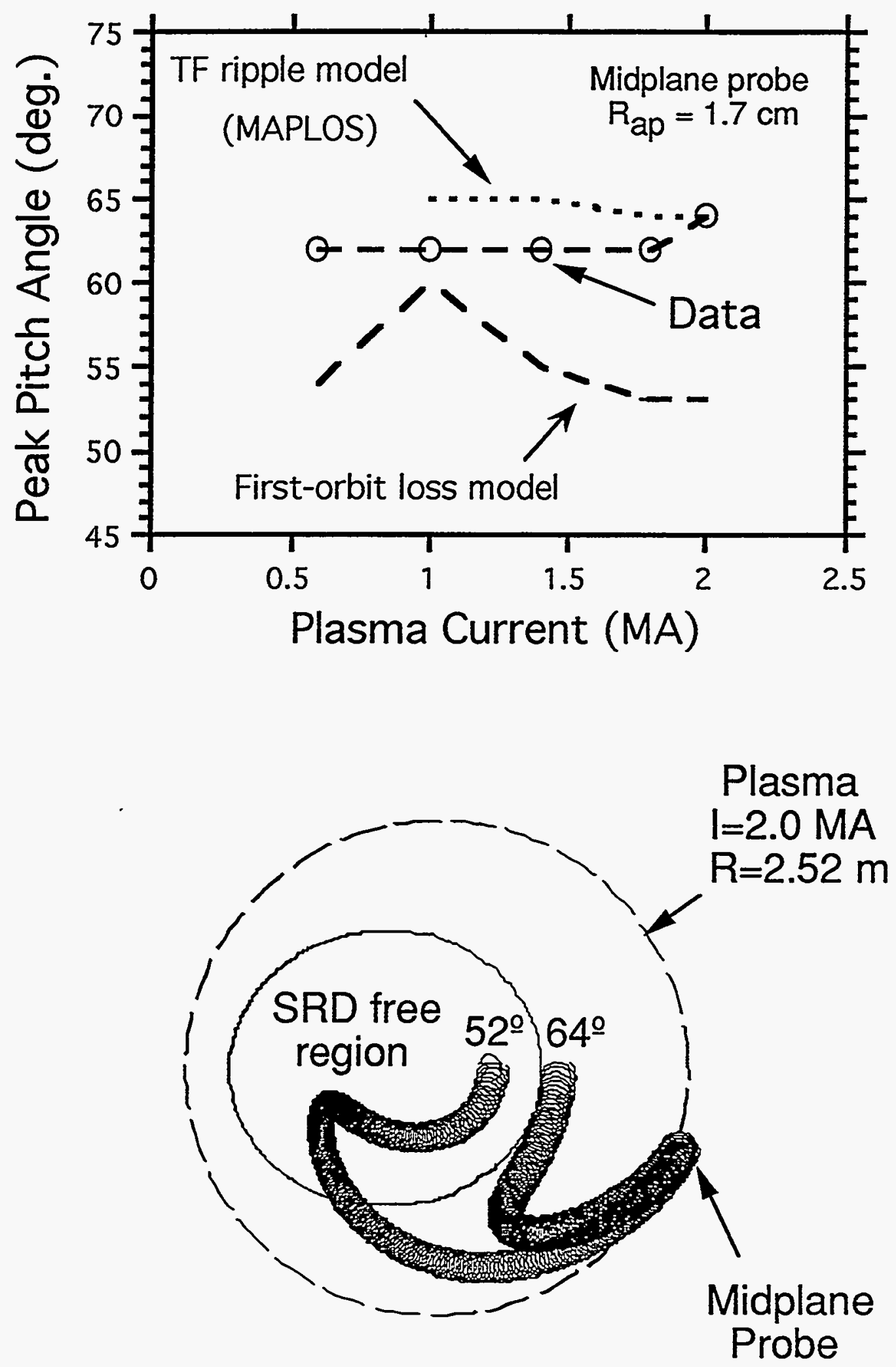

Fig. 10 
Dr. F. Paoloni, Univ. of Wollongong, AUSTRALIA

Prof. R.C. Cross, Univ. of Sydney, AUSTRALIA

Plasma Research Lab., Australian Nat. Univ., AUSTRALIA

Prof. I.R. Jones, Flinders Univ, AUSTRALIA

Prof. F. Cap, Inst. for Theoretical Physics, AUSTRIA

Prof. M. Heindler, Institut für Theoretische Physik, AUSTRIA

Prof. M. Goossens, Astronomisch Instituut, BELGIUM

Ecole Royale Militaire, Lab. de Phy. Plasmas, BELGIUM

Commission-European, DG. XII-Fusion Prog., BELGIUM

Prof. R. Bouciqué, Rijksuniversiteit Gent, BELGIUM

- Dr.P.H. Sakanaka, Instituto Fisica, BRAZIL

Prof. Dr. I.C. Nascimento, Instituto Fisica, Sao Paulo, BRAZIL Instituto Nacional De Pesquisas Espaciais-INPE, BRAZIL Documents Office, Atomic Energy of Canada Lid., CANADA

Ms. M. Morin, CCFMTtokamak de Varennes, CANADA

Dr. M.P. Bachynski, MPB Technologies, inc., CANADA

Dr. H.M. Skarsgard, Univ. of Saskatchewan, CANADA

Prof. J. Teichmann, Univ. of Montreal, CANADA

Prof. S.R. Sreonivasan, Univ. of Calgary, CANADA

Prof. R. Marchand, INRS-Energie et Materiaux, CANADA

Dr. A. Bolton, Centre canacien de fusion magnétique, CANADA

Dr. C.R. James, Univ. of Alberta, CANADA

Dr. P. Lukác, Komenského Universzita, CZECHO-SLOVAKIA

The Librarian, Culham Laboratory, ENGLAND

Library, R61, Rutherford Appleton Laboratory, ENGLAND

Mrs. S.A. Hutchinson, JET Library, ENGLAND

Dr. S.C. Shama, Univ. of South Pacific, FIJI ISLANDS

P. Mähönen, Univ. of Helsinki, FINLAND

Prof. M.N. Bussac, Ecole Polytechnique, FRANCE

C. Mouttet, Lab. de Physique des Milieux lonisés, FRANCE

J. Radet, CEN/CADARACHE - Bat 506, FRANCE

Prof. E. Economou, Univ. of Crete, GREECE

Ms. C. Pinni, Univ. of loannina, GREECE

Preprint Library, Hungarian Academy of Sci., HUNGARY

Dr. B. DasGupta, Saha Inst. of Nuclear Physics, INDIA

Dr. P. Kaw, Inst. for Plasma Research, INDIA

Dr. P. Rosenau, Israel Inst of Technology, ISRAEL

Librarian, Intemational Center for Theo Physics, ITALY

Miss C. De Palo, Associazione EURATOM-ENEA , ITALY

Dr. G. Grosso, Istituto di Fisica del Plasma, ITALY

Prof. G. Rostangni, Istituto Gas lonizzati Del Cnr, ITALY
Dr. H. Yamato, Toshiba Res \& Devel Center, JAPAN

- Prof. I. Kawakami, Hiroshima Univ., JAPAN

Prof. K. Nishikawa, Hiroshima Univ., JAPAN

Libraian, Naka Fusion Research Establishment, JAERI, JAPAN

Director, Japan Atomic Energy Research Inst., JAPAN

Prof. S. Itoh, Kyushu Univ., JAPAN

Research Info. Ctr., National Instit. for Fusion Science, JAPAN

Prof. S. Tanaka, Kyoto Univ., JAPAN

Library, Kyoto Univ., JAPAN

Prof. N. Inoue, Univ. of Tokyo, JAPAN

Secretary, Plasma Section, Electrotechnical Lab., JAPAN

Dr. O. Mitarai, Kumamoto Inst. of Technology, JAPAN

Dr. G.S. Lee, Korea Basic Sci. Ctr., KOREA

J. Hyeon-Sook, Korea Atomic Energy Research Inst, KOREA

D.I. Choi, The Korea Adv. Inst. of Sci. \& Tech., KOREA

Leandro Melendez Lugo, Inst. Nacy. de Inves. Nucl, MEXICO

Prof. B.S. Liley, Univ. of Waikato, NEW ZEALAND

Inst of Physics, Chinese Acad Sci PEOPLE'S REP. OF CHINA

Library, Inst. of Plasma Physics, PEOPLE'S REP. OF CHINA

Tsinghua Univ. Library, PEOPLE'S REPUBLIC OF CHINA

Z. L, S.W. Inst Physics, PEOPLE'S REPUBLIC OF CHINA

Prof. J.A.C. Cabral, Instituto Superior Tecrico, PORTUGAL

Prof. M.A. Hellberg, Univ. of Natal, S. AFRICA

Prof. D.E. Kim, Pohang Inst. of Sci. \& Tech., SO. KOREA

Prof. C.I.E.M.A.T, Fusion Division Library, SPAIN

Dr. L. Stenflo, Univ. of UMEA, SWEDEN

Library, Royal inst. of Technology, SWEDEN

Prof. H. Wilhelmson, Chalmers Univ. of Tech., SWEDEN

Centre Phys. Des Plasmas, Ecole Polytech, SWITZERLAND

Bibliotheek, Inst. Voor Plasma-Fysica, THE NETHERLANDS

Asst. Prof. Dr. S. Cakir, Middle East Tech. Univ., TURKEY

Dr. V.A. Glukhikh,Sci. Res. Inst. Electrophys.I Apparatus, USSR

Dr. D.D. Ryutov, Siberian Branch of Academy of Sci., USSR

Dr. G.A. Eliseev, I.V. Kurchatov Inst., USSR

Librarian, The Ukr.SSR Academy of Sciences, USSR

Dr. L.M. Kovrizhnykh, Inst. of General Physics, USSR

Kemforschungsanlage GmbH, Zentralbibliothek, W. GERMANY

Bibliothek, Inst. Für Plasmaforschung. W. GERMANY

Prof. K. Schindler, Ruhr-Universitát Bochum, W. GERMANY

Dr. F. Wagner, (ASDEX), Max-Planck-Institut, W. GERMANY

Librarian, Max-Planck-Institut, W. GERMANY 